\title{
Avaliação de Uma Rede Neural Artificial Como Modelo Regressor Para Séries Temporais
}

\author{
João Vitor Alves da Cruz \\ Intituto Federal de Educação, Ciência e Tecnologia de Minas Gerais - IFMG Campus \\ Bambuí, Brasil.
}

Bruno Alberto Soares Oliveira

Universidade Federal de Minas Gerais, Brasil.

Resumo: Técnicas de predição de demanda são utilizadas em inúmeros ramos da indústria, com o objetivo de agregar valor ao negócio das empresas, especialmente por meio da busca pelo dimensionamento ótimo dos recursos de produção. A predição de demanda em refeitórios, com o intuito de balancear a quantidade de alimento produzido, buscando um melhor aproveitamento dos ingredientes, é um desafio, pois fatores como a quantidade de usuários, o tempo de atendimento e o tipo de alimento utilizado podem ser bastante variáveis neste tipo de problema. O estudo das filas, neste contexto, é de primordial importância, dado que, conhecendo suas características, podem-se estimar, por meio de previsão, informações que podem melhorar a qualidade de atendimento. $\mathrm{O}$ presente trabalho teve por finalidade utilizar modelos baseados em Redes Neurais Artificiais (RNA) para realizar regressões em uma série temporal personalizada, gerada por meio de metodologia própria, mediantes os dados coletados in loco no restaurante do IFMG - Campus Bambuí. Teve-se por principal objetivo desenvolver um modelo computacional que fosse capaz de descrever o comportamento para os intervalos de tempo no atendimento dos usuários. Por meio deste recurso, pôde-se gerar informações importantes para a tomada de decisão, como os horários de maior e menor pico de atendimento.

Palavras-chave: Redes neurais artificiais, regressão, séries temporais.

Abstract: Demand prediction techniques are used in numerous industry sectors with the aim of adding value to the business of the companies, especially through the search for optimal sizing of production resources. The prediction of demand in restaurants with the intention of balancing the quantity food produced looking for better use of ingredients is a challenge, since factors like the quantity of users, the time of service and the kind of food can be quite variable in this type of problem. The study of queue, in this context, is of paramount importance, given that, knowing its characteristics, it is possible to estimate, by means of prediction, information that can improve service quality. Present work had the purpose of using models based on Artificial Neural Networks (ANN) to perform regressions in a personalized time series, generated through its own methodology with data collected in the restaurant of the IFMG - Campus Bambuí. The main objective was to develop a computational model that would be able to describe the behavior for the time intervals in the restaurant customer service. Through this resource, it was possible to generate important information for decision making, such as the peak times of higher and lower demands.

Keywords: Artificial neural networks, regression, time series.

Corresponding author: Bruno Alberto Soares Oliveira, brunoalbertobambui@ufmg.br

Received: 12 Dec 2020 / Accepted: 04 Jan 2021 / Published: 21 Mar 2021.

\section{Introdução}

A aplicação de métodos inteligentes, no que se refere a algoritmos e técnicas computacionais, permite flexibilizar a resolução de problemas, alcançando resultados de

CALIBRE - Revista Brasiliense de Engenharia e Física Aplicada Copyright \& 2017, Faculdades ICESP maneira rápida e viável. Nesse sentido, eles podem ser utilizados no ramo da predição de demanda, com o intuito de agregar valor aos negócios de empresas diversas.

O emprego destas técnicas em refeitórios, por exemplo, pode ser bastante interessante em relação ao estudo de filas, dado que, conhecendo suas características, podese estimar, por meio de uma previsão, informações úteis 
aos usuários que anseiam pelo atendimento. Desse modo, o uso de métodos baseados em Redes Neurais Artificias, visando gerar um modelo de regressão com séries de tempos, pode ser uma opção viável para esse tipo de problema.

As Redes Neurais Artificiais (RNA) funcionam, teoricamente, de maneira semelhante ao cérebro humano, visando reconhecer características e padrões de dados. Assim sendo, objetivam ser capazes de aprender, por meio de um treinamento, e fazer generalizações baseadas no conhecimento previamente acumulado. Uma área em que as RNA são aplicadas é na previsão para séries de tempo 21].

O processo de previsão de dados futuros é considerado uma importante ferramenta para o planejamento de qualquer organização. Dentro da análise de séries temporais, existem diversos modelos, com as mais variadas suposições quanto ao comportamento de uma série de dados [14.

A principal técnica utilizada neste trabalho foi a de RNA, a qual se ajusta por meio dos dados de entrada, fornecidos por um registro de filas, para se gerar uma regressão. O emprego de RNA é justificável por sua capacidade de reconhecimento de padrões e ajuste funcional, permitindo alcançar bons resultados, de forma geral.

O refeitório do IFMG-Campus Bambuí atende alunos, servidores e visitantes. Este fator faz com que seja necessário um estudo relacionado à demanda de pessoas no local. Um problema muito comum enfrentado pelos seus usuários é o congestionamento da fila, podendo gerar uma grande demora no atendimento devido ao elevado número de pessoas que anseiam pelo serviço, principalmente em horários de pico. Oliveira et al. [12] também desenvolveu um trabalho no IFMG-Campus Bambuí em que foi possível verificar a possibilidade da inserção de meios tecnológicos para auxiliar na tomada de decisão dos processos que ocorrem no local abordado dessa pesquisa.

Assim, justifica-se o uso de uma RNA com os dados do refeitório, uma vez que ela permite fazer uma estimativa de comportamento do local em seu funcionamento, podendo servir de auxílio, com as informações extraídas, para a tomada de decisão dos usuários em um horário de almoço.

O trabalho de Rodriguez e Corrêa [16] se propôs a encontrar o método mais eficiente para a previsão da demanda de peças em sistemas de refrigeração latinoamericanos. Foram usadas técnicas diversas, a fim de selecionar aquela que obtivesse o melhor resultado. A técnica de RNA foi a que se destacou para a previsão das demandas de peças.

Sigauke [17] fez uma aplicação de Modelos Aditivos Generalizados (MAG) em uma previsão de demanda de eletricidade usando dados sul-africanos, nos anos de 2009 a 2013. Foi realizado um estudo em que se aplicaram técnicas de tratamento, antecipadamente acerca dos dados, e, logo após, fez-se o uso combinado de técnicas inteligentes. Os resultados finais demonstraram uma melhor eficiência na previsão esperada.
No trabalho de Oliveira et al. 13] foi avaliada a aplicação de uma Rede Neural Artificial Perceptron MultiCamadas utilizando como objeto de aplicação os dados de pluviometria acumulada mensal oriundos do Sistema Cantareira. O treinamento da MLP foi realizado tomando-se por base as medições pluviométricas de outros cinco grandes sistemas brasileiros. Os resultados obtidos mostraram que foi possível cumprir o objetivo proposto e validar a MLP como alternativa válida à substituição, em casos oportunos, aos métodos de medição convencionais

Tello-Maita e Marulanda-Guerra 19] descreveram um estudo que teve por objetivo utilizar modelos que permitiram a otimização em sistemas de potência. Nesse sentido, foram considerados aspectos como energias renováveis e sua variabilidade, geração distribuída e microrredes, gerenciamento de demanda e sistemas do armazenamento de energia. Fez-se, assim, a abordagem na utilização de técnicas modernas no que diz respeito à RNA, a fim de obter resultados promissores, aplicados na gestão de demanda. Foi verificado um impacto nos custos gerados, dentro dos setores produtivos.

Valencia-Cárdenas et al. [20] apresentaram uma comparação para modelos de previsão da demanda em múltiplos produtos, dentre os seguintes métodos; Média Móvel Autorregressiva Integrada (Autoregressive Integrated Moving Average, ARIMA), Suavização Exponencial (SE), um Modelo Bayesiano de Regressão (Bayesian Regression Models, BRM) e um Modelo Linear Dinâmico Bayesiano (Bayesian Dynamic Linear Models, BDLM). O trabalho baseou-se em testar tais métodos para o setor de estoques em diferentes empresas. Assim sendo, foram extraídas informações que permitiram a minimização dos custos e a maximização de lucros.

O trabalho realizado por Staudt et al. [7] tratou da inserção dos modelos de previsão dentro dos setores empresariais e como isso pode impactar diretamente na melhoria da qualidade de seus serviços. Foi relatado como é necessária a implantação de um processo estruturado para realizar a previsão, evitando os possíveis viéses e limitações do julgamento humano, que comprometem o desempenho e a credibilidade das previsões.

Srisaeng et al. [18] propuseram e testaram empiricamente, pela primeira vez, modelos da otimização de algoritmos genéticos para modelar a demanda de passageiros em companhias aéreas domésticas da Austrália. Os dados foram divididos em conjuntos de treinamento e teste, em que 74 deles, foram utilizados para estimar os fatores de ponderação dos modelos de algoritmos genéticos, e outros 13, fora da amostra, foram utilizados para testar a sua robustez. A técnica se mostrou útil, com baixos percentuais de erros.

Guarnieri [6] desenvolveu e avaliou uma metodologia de previsão na irradiação solar incidente, constituindo uma pesquisa de meteorologia aplicada, estabelecida no refinamento da previsão numérica de tempo produzida pela metodologia do Eta/CPTEC. As variáveis de saída do modelo foram empregadas como preditores em modelos de RNA e RLM, ajustados para calcular a radiação 
solar incidente para duas localidades em que se situam estações do projeto SONDA. Parâmetros de avaliação de erros, determinados frente aos dados observacionais de cada estação de medida, foram calculados para cada previsão, a cada teste, permitindo a comparação de RNA e RLM. Obteve-se, como resultado, um ganho nas previsões da radiação solar de curto prazo, ao passo que, foi verificado não ocorrer ganho significativo em desempenho com técnicas convencionais.

Mahmoodi e Naderi [8], em seu trabalho, fizeram uso de RNA e Regressão Não Linear(RNL) para obter uma estrutura de grão ultrafino com as propriedades ECAR (Equal Channel Angular Rolled ). Uma RNA foi usada para prever as propriedades mecânicas das folhas AI5083 (tipo de liga de alumínio). Os parâmetros de entrada e as propriedades mecânicas foram extraídos separadamente, usando o método de regressão linear. Os desempenhos da RNA e do modelo de RNL mostraram que ambos estimaram, com precisão, as propriedades mecânicas das amostras de Al5083, com ECAR. No entanto, o modelo de RNA determinou os parâmetros de saída com alta precisão.

Baptistella et al. 11 compararam as técnicas de RNA e RLM na estimação dos valores de venda de imóveis urbanos da cidade de Guarapuava/PR. O modelo inicial foi composto por treze variáveis do referido cadastro, sendo elas: bairro, setor, pavimentação, esgoto, iluminação pública, área do terreno, pedologia, topografia, situação, área edificada, tipo, estrutura e conservação. As RNA foram desenvolvidas utilizando o algoritmo de treinamento "Levenberg Marquardt" com uma camada oculta. Na comparação das duas técnicas, embora tenham apresentado resultados semelhantes, as Redes Neurais Artificiais apresentaram desempenho superior.

Assim como nos trabalhos citados que utilizaram RNA para séries temporais, essa pesquisa teve como proposta a aplicação de uma RNA para extrair informações em dados coletados durante o funcionamento do restaurante, a fim de informar horários de pico, e, assim, usar tais informações para a melhora na eficiência de atendimento.

Foi desenvolvido um método para a coleta dos dados, e, após isso, gerou-se um dataset para avaliar o melhor método de análise e tratamento destes. Tal estudo, baseado nesse conjunto de dados, foi realizado durante o período do almoço no campus, devido à maior demanda. Com este trabalho, esperou-se gerar uma regressão, com uma série de intervalos de tempos extraídos dos dados coletados, para que, com o uso de uma RNA, fosse possível extrair informações, e, assim, fazer um levantamento de estatísticas úteis aos usuários.

\section{Fundamentação Teórica}

\subsection{Análise e planejamento de experimentos}

Para a realização de qualquer experimento, há a necessidade de se organizar antecipadamente. Assim sendo, um esboço claro dos passos que devem ser realizados é necessário, para que os objetivos sejam atingidos [11].

Nesse sentido, de acordo com Neto et al. [11, na percepção do senso comum, o trabalho com métodos estatísticos baseia-se em uma mineração bem-sucedida, que explora e processa milhares de informações, a fim de extrair conclusões de grande valor. Mas esta é uma impressão falsa, uma vez que a atividade estatística de maior importância é o planejamento de experimentos, em como os dados serão apanhados. Com uma má realização dessa etapa, o resultado se torna uma pilha gigantesca de números sem sentido. Por esse motivo, um bom planejamento consiste em projetar um experimento de maneira que seja fornecido o tipo de informação procurada, para, assim, realizar uma análise. Dependendo do que se almeja, algumas técnicas são vantajosas, ao passo que outras são totalmente dispensáveis.

\subsection{Sistemas e algoritmos inteligentes}

Para Wilamowski e Irwin 22, entende-se por algoritmos inteligentes aqueles capazes de realizar a autoaprendizagem e resolverem, por si próprios, algum problema que um algoritmo determinístico, no seu escopo de ação, não possuiria tanta efetividade. Dentre eles, se aplicam as Redes Neurais Artificiais, os algoritmos genéticos e outros métodos de computação natural.

Dentro dos sistemas de aprendizado, podem ser abordadas duas maneiras de classificação em categorias: a primeira se dá por um tipo de caixa-preta, que manifesta sua própria representação do conceito, isto é, seu aspecto interno não pode ser facilmente interpretado por humanos, não sendo esclarecido e não havendo uma explicação do processo de reconhecimento. Já o segundo são os sistemas orientados a conhecimento, que objetivam a criação de estruturas típicas que sejam compreensíveis por humanos 22.

Neste trabalho, pretendeu-se aplicar este tipo de conhecimento, dado que, no problema de interesse, oportuniza-se o uso de modelagens que visam otimizar, de forma autônoma, a demanda do tempo de fila, com base em um dataset. Em outras palavras, procurou-se aplicar algum algoritmo inteligente, para buscar a solução do problema.

\subsection{Análise de demanda e previsão}

Segundo Gaither e Frazier [5, predizer, ou medir, a demanda futura de produtos, serviços e os recursos necessários para produzi-los é o primeiro passo da etapa do planejamento. Nesse sentido, a predição se torna uma ferramenta poderosa para qualquer situação que exija, quantitativamente, materiais específicos.

Com o estudo de demanda, pode-se criar um modelo de previsão aplicado, seja ele um método estatístico ou computacional. Para Moreira [10], os métodos de previsão podem ser classificados de acordo com critérios variados. No entanto, a classificação mais comum é a que leva em consideração o tipo de abordagem utilizada, ou 
seja, os tipos de instrumentos e conceitos que formam a base da previsão. Por este critério, os métodos podem ser qualitativos e quantitativos.

Dado este contexto, a análise de demanda se faz importante neste trabalho, pois ela se apresentou como pilar para averiguar o que poderia ser melhorado, sendo utilizada para a construção do modelo de previsão.

\subsection{Redes Neurais Artificiais}

O estudo das Redes Neurais Artificiais (RNA) foi inspirado no sistema biológico humano, simulando o sistema nervoso central, ou seja, capazes de realizar o aprendizado de máquina (Machine Learning) e o reconhecimento de padrões. É um modelo simplificado e simulado do neurônio real. Sua representação pode ser vista na Figura 1. sendo essa também denominada de Perceptron, em que diversas entradas atuam como mapeamento de um problema, e, nesse sentido, elas são processadas, de maneira que os pesos e o limiar de ativação (funções como degrau, linear ou sigmoide) permitam que determinadas entradas sejam efetivas na abstração da RNA, gerando uma saída como resultado. São uma forma de computação caracterizada por sistemas que, em algum nível, lembram a estrutura de raciocínio do cérebro humano 4 .

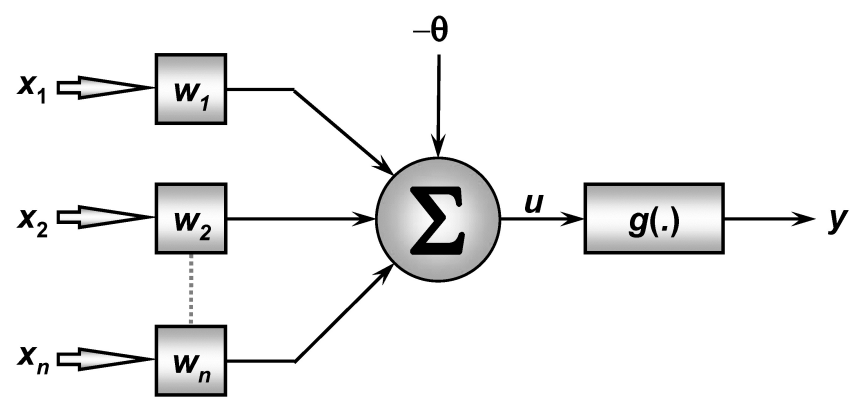

Figura 1: Esquema de uma RNA simples (Perceptron)

Fonte: Silva et al. [3]

As características básicas das RNA são a adaptação e a representação de conhecimentos baseados em conexões, as quais são dadas por entradas que estão integradas, com pesos que simulam os estímulos sinápticos, realizados por um cérebro. Quando essas estradas ultrapassam o potencial de ativação, esta é indicada como válida ou não. Para Manuel e Pretorius 9, uma Rede Neural Artificial pode ser considerada um processador paralelo e distribuído, composto por várias camadas de neurônios. A primeira camada é referida como a camada de entrada, e a última, como camada de saída. Entre as camadas de entrada e saída, várias outras podem existir.

Para Silva et al. [3], quando uma RNA possui pelo menos uma camada intermediária, esta é denominada como Perceptron de múltiplas camadas (PMC), a qual possui, no mínimo, duas camadas, dividas entre intermediárias e de saída, sua representação pode ser vista na Figura 2. É considerada como uma das arquiteturas mais versáteis, tendo ampla aplicabilidade, como, por exemplo, na aproximação universal de funções. Seu treinamento é dado de maneira supervisionada, ou seja, são conhecidas as saídas durante o processo de treinamento, feito por meio do algoritmo denominado backpropagation.

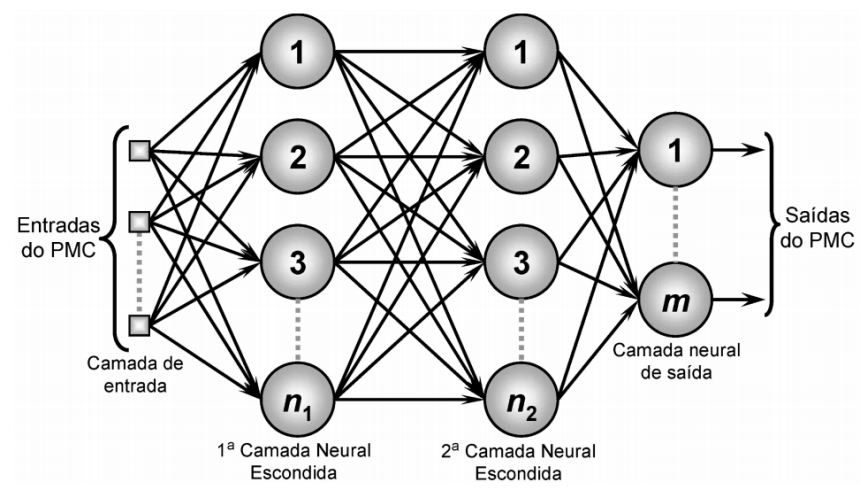

Figura 2: Esquema de uma Perceptron de múltiplas camadas

Fonte: Silva et al. [3]

Esta será uma das principais técnicas abordadas no trabalho, visando à aplicação dos dados coletados durante o período experimental.

\subsection{Análise e tratamento de dados}

De acordo com Reimann et al. [15, a análise de dados estatísticos trata do estudo de dados graficamente ou por meio de métodos mais formais. As técnicas de Análise Exploratória de Dados (Exploratory Data Analysis, EDA) fornecem muitas ferramentas que transferem grandes e complicadas tabulações de dados, para exibições gráficas fáceis de entender, que são independentes das suposições sobre os dados, e que são usados para "visualizar" os dados.

Nesse sentido, os itens de amostras que se apresentam com um grande afastamento dos restantes ou como sendo inconsistentes são habitualmente designados por outliers. Para Barnett e Lewis [2, tal termo é caracterizado por sua relação com as observações restantes, que fazem parte da amostra. O seu distanciamento em relação a esses dados é fundamental para fazer a sua caracterização. Estes elementos são, também, designados como "anormais"ou contaminantes.

\section{Metodologia}

A pesquisa realizada foi caracterizada como aplicada, quantitativa e em campo, uma vez que os seus conhecimentos podem ser aplicados na vida real, fazendo-se uso de ferramentas e técnicas estatísticas com os dados coletados, ao passo que, para eles existirem, houve a necessidade de o pesquisador observar um ambiente para a realização das atividades propostas. 


\subsection{Delineamento do experimento}

O primeiro passo para a construção do dataset utilizado no trabalho foi realizar um estudo sobre coletas de dados, verificando quais etapas básicas deveriam ser realizadas. Para isso, foram analisadas as possibilidades de estruturação para coleta, bem como uma investigação de problemas que pudessem inviabilizar o experimento.

Antes de iniciar o trabalho experimental, houve reuniões com a nutricionista do campus, pois ela é a responsável pelo gerenciamento do refeitório. Foram levadas as propostas para o desenvolvimento do trabalho, e, nesse sentido, discutiram-se todas as questões de permissões e limitações do que poderia ser realizado.

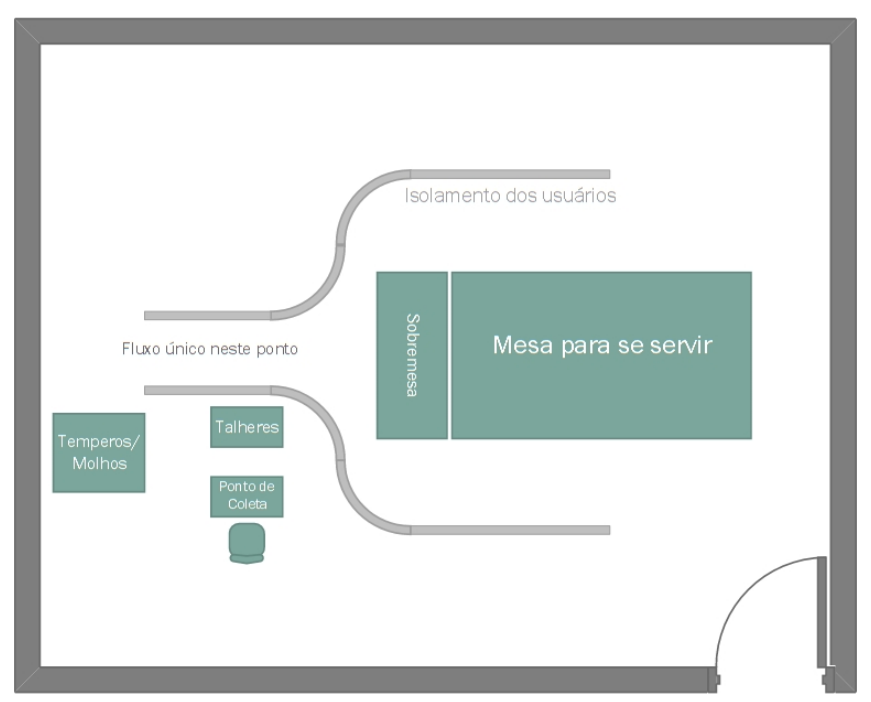

Figura 3: Esquema construído para disposição do refeitório

Fonte: acervo do autor

Esse levantamento de regras foi necessário, pois houve algumas adequações aplicadas ao funcionamento do refeitório. Com isso, foi criado um esquema, representado pela Figura 3 , de como o ambiente ficou disposto durante a realização das coletas, demonstrando o posicionamento de cada componente.

\subsubsection{Materiais}

Durante a realização da coleta, foi utilizado um computador pessoal com Windows 8.1 e planilha eletrônica. As configurações do computador eram de um processador Core i7, com 8GB de RAM. O uso da planilha foi importante no processo, para registrar os horários e, por conseguinte, os intervalos de atendimento dos usuários.

Para isso, foi implementada uma macro, a qual capturava a data e o horário, no formato hh:mm:ss, e, implicitamente, também contando o número de pessoas na fila para o dia em questão. A ação da macro ocorria por meio do clique em um botão virtual inserido no software da planilha.

Também nesta etapa, foi construída uma tabela, cujo objetivo era registrar os dados dos alimentos de cada dia. Tal tabela, representada na Figura 4, foi repassada para os responsáveis por coordenar as atividades dentro da cozinha, uma vez que ela só poderia ser acessada por pessoas autorizadas, devido a regras de salubridade do local.

Figura 4: Representação da tabela de dados sobre os alimentos

Coleta de Dados Refeitório IFMG
Data:
\begin{tabular}{|l|l|l|l|l|l|l|l|l|}
\hline Alimento & & & & & & & & \\
\hline Quantidade Crua & & & & & & & & \\
\hline $\begin{array}{l}\text { Uuantidade } \\
\text { Cozida }\end{array}$ & & & & & & & & \\
\hline $\begin{array}{l}\text { Suantidade } \\
\text { Sobra Cruan } \\
\text { Quantidale }\end{array}$ & & & & & & & & \\
\hline Sobra Cozida & & & & & & & & \\
\hline Status Final & & & & & & & & \\
\hline
\end{tabular}

Obs: A quantidade deve ser de acordo com a unidade de medida usada pelo refeitorio, $\mathrm{kg}$, litros, unidade etc.

Algum alimento faltou?

\begin{tabular}{|l|l|}
\hline Alimento & Horário de Falta \\
\hline
\end{tabular}

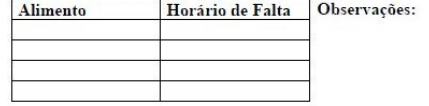

Fonte: acervo do autor

Com isso, foi necessário rearranjar tais tabelas em arquivos .csv, para que fossem inseridos dentro dos requisitos do software RStudio, utilizando a linguagem R.

\subsubsection{Condução do experimento}

Na realização do experimento das coletas, foram analisadas várias possibilidades dentro das limitações do refeitório. Houve algumas alternativas para se realizar as coletas, entre elas, o uso de sensores e botões, de maneira que, quando o aluno terminasse de se servir, ele iria se autorregistrar.

Nesse ponto, ficou evidente que a melhor escolha foi desenvolver uma maneira de captura pelo próprio autor do dataset, já que, dessa forma, o padrão de coleta se daria de maneira regular, evitando muitas variações e minimizando a quantidade de erros na geração final dos dados.

A estratégia se deu em posicionar o computador de frente aos talheres, uma vez que estes são de uso essencial para a alimentação, bem como representam, de maneira ideal, o ponto em que o usuário termina de se servir. A fila também sofreu algumas alterações, com o uso de pedestais para orientar as pessoas no caminho que deviam seguir, bem como para limitar a passagem de uma pessoa por vez no momento em que os talheres fossem apanhados. O esquema real, em seu funcionamento, está representado na Figura 5 .

\subsection{Características da Fila}

O processo básico de filas, em geral, acontece quando clientes anseiam por um atendimento. Essa fase é denominada como fonte de entrada. Logo após, esses usuários passam por um processo de sistema de filas, em que, de tempos em tempos, um determinado integrante é selecionado por alguma regra, conhecida como disciplina da 




Figura 5: Imagem registrada em um dos dias do experimento

Fonte: acervo do autor

fila, e, assim, o atendimento é realizado de acordo com seus mecanismos, e o cliente é liberado.

Desse modo, a fila na qual foram extraídos os dados classifica-se como uma fonte de entrada de tamanho limitado, pois há um limite no tempo de atendimento para os serviços do refeitório, que é por volta de uma hora e meia. Assim sendo, a própria fila também se denominou como finita, em que o número máximo de usuários atendidos em todos os dias coletados não ultrapassou 900 pessoas.

Conduzindo ainda a fila observada, a sua disciplina foi determinada como FIFO (First In First Out), ou seja, o primeiro que chega é o primeiro a ser atendido. E assim, numa etapa inicial, foi dada por um fluxo único em sua formação, em que foi trocado por um fluxo duplo durante o processo de se servir e, imediatamente após, a fila passou a ser de fluxo único novamente, com o objetivo de se pegar os talheres. O ponto de coleta se deu nesse último fluxo. Assim, a fila observada para a coleta pode ser classificada, de maneira geral, como fluxo único.

Diante disso, realizados os procedimentos de delineamento e de como a fila se dava, partiu-se para o processo de construção do dataset.

\subsection{Geração do dataset}

Após realizada a coleta, partiu-se para a verificação da disposição dos dados e a elaboração de um planejamento. Com isso, foram analisadas possíveis maneiras de organizá-los, para, assim, potencializar os resultados quando fossem inseridos no contexto do problema.

Nessa etapa, procurou-se elucidar como ficariam dispostas as estruturas dos datasets. Foi decidido que haveria pelo menos dois tipos de base de dados: uma destinada à frequência e aos registros da fila, e outra para os alimentos com os dados referentes a quantidades produzidas, sobras, falta de alimentos e horários em que acabaram. A princípio, havia a intenção de se usar dados dos alimentos na predição, mas não foram utilizados, pois decidiu-se, durante o estudo, abranger apenas o escopo da fila, pelo fato da inviabilidade de uma análise precisa desses dados durante o desenvolvimento da pesquisa.

O formato do dataset consistiu em uma tabela contendo data e hora para cada registro que acontecia nos momentos de coleta, e, assim, foram feitas as conversões para o tipo .csv, sendo inseridos no contexto do software usado. Tal etapa se fixou no tratamento de dados de maneira a remover possíveis interferências que gerassem ruídos no conjunto de dados.

\subsubsection{Tratamento e disposição dos dados}

Nesta fase, fazendo-se uso das ferramentas gráficas do RStudio, os dados foram aplicados em alguns tipos de gráficos, a fim de verificar, visualmente, o seu comportamento. Além disso, foi utilizado um método de ajuste de outliers, visando à lapidação dos elementos do dataset. A função que realizou esse procedimento, basicamente, divide a distribuição da amostra em quatro quartis, e os elementos que se encontram fora do segundo e terceiro quartis são removidos e adequados de acordo com os valores mais próximos, por exemplo, pegando os vizinhos da direita e esquerda e calculando a metade de sua soma. Assim sendo, para o dia 04/05/2019, na Figura 6 verificam-se os gráficos de frequência, demonstrando a disposição dos intervalos para todos os usuários ao longo do tempo, antes e após o tratamento.
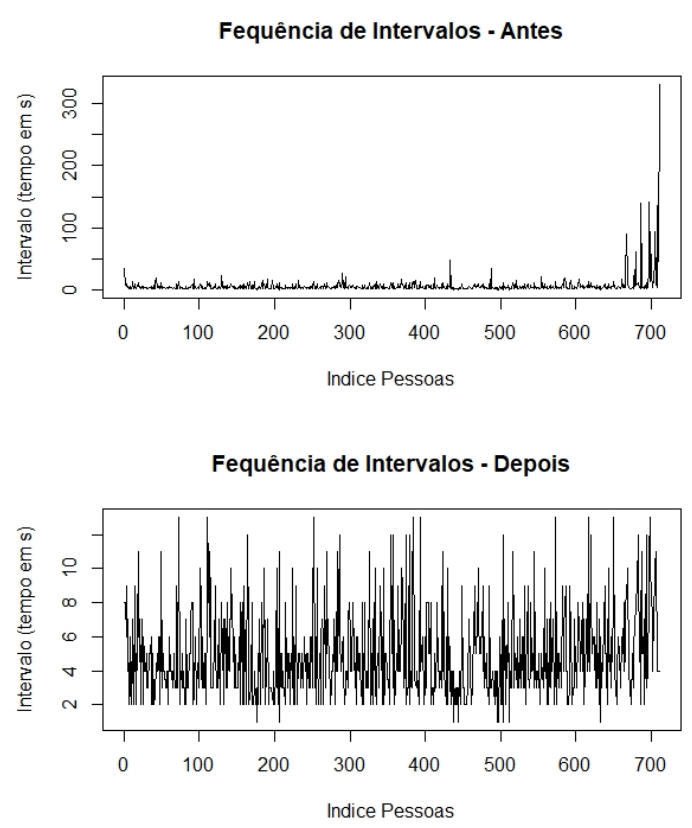

Figura 6: Gráficos de frequência do dia 04/05/2019, antes e após o tratamento

\section{Fonte: acervo do autor}

Observado o gráfico de frequência, tornou-se necessária a aplicação desses dados em um histograma, como demonstrado na Figura 7 , permitindo observar quais intervalos mais se repetiram ao longo daquele período.

Na sequência, foi utilizado um gráfico de dispersão com o intuito de verificar outliers. Como demonstrado na Figura 8, foi aplicado um gráfico boxplot em que cada um dos pontos fora da faixa-padrão representa elementos dispersos. 




Histograma - Depois

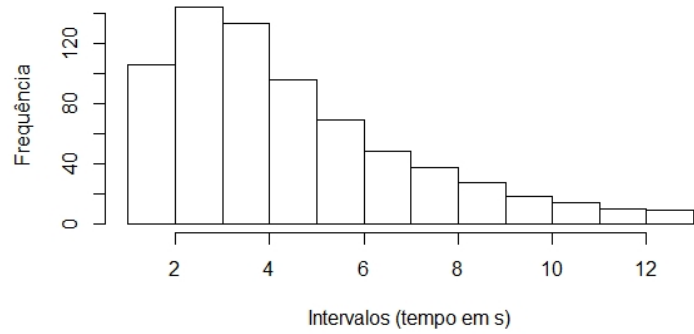

Figura 7: Gráficos de histograma do dia 04/05/2019, antes e após o tratamento

Fonte: acervo do autor
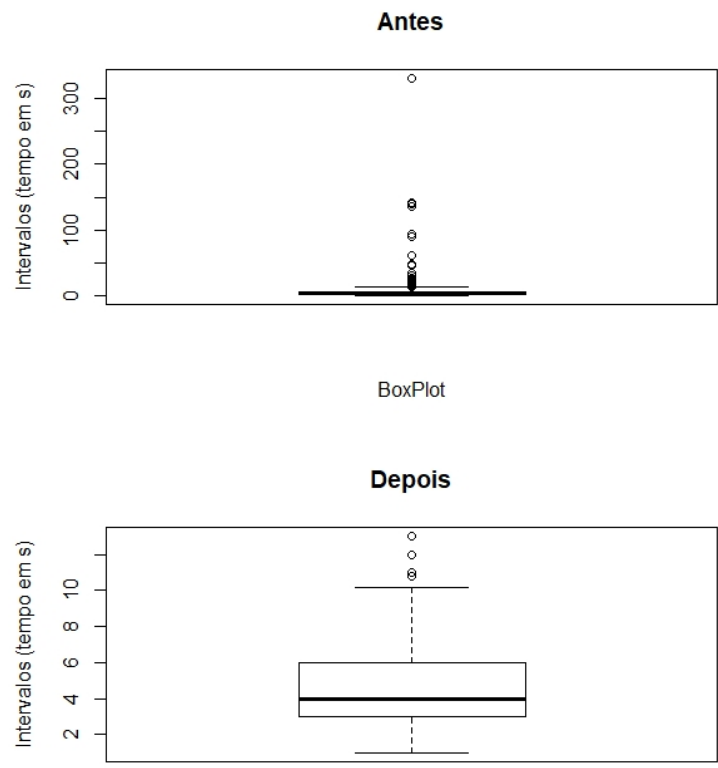

BoxPlot

Figura 8: Gráficos de boxplot do dia 04/05/2019, antes e após o tratamento

Fonte: acervo do autor

Com isso, para aprimorar essa verificação, foi usado um gráfico de aderência a uma distribuição normal, como mostra a Figura 9. Dessa forma, procurou-se identificar quais valores se encontravam fora do alinhamento.

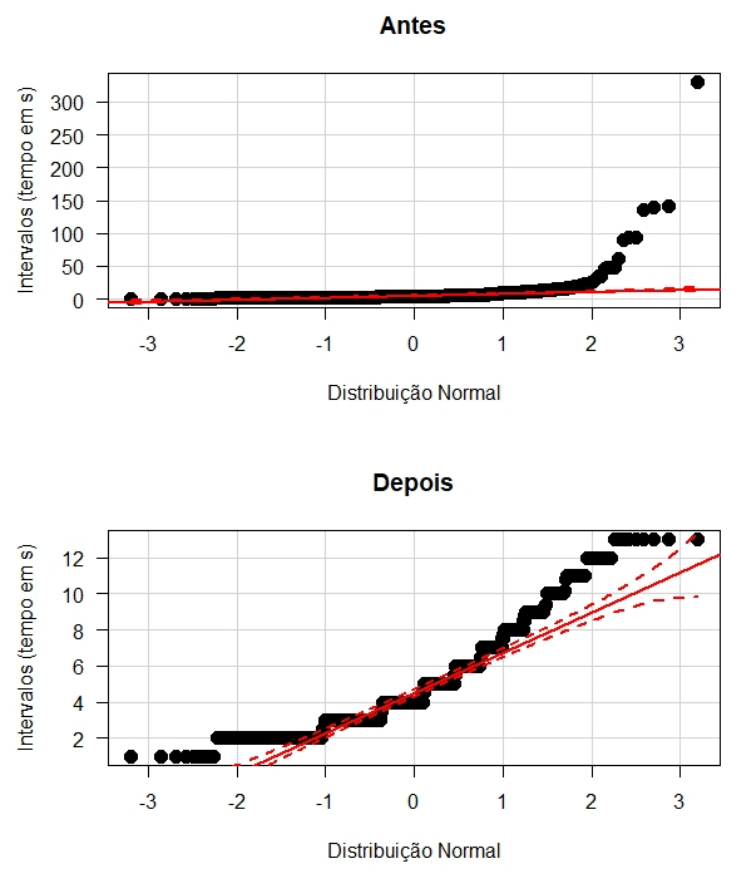

Figura 9: Gráficos da distribuição normal do dia 04/05/2019, antes e após o tratamento

Fonte: acervo do autor

\subsection{Construção do algoritmo de previsão}

Este ponto teve como principal objetivo distinguir e mostrar técnicas computacionais que foram abordadas, demonstrando suas implementações para se encaixar dentro das estratégias de montagem do dataset, bem como para o problema tratado.

Foi abordado o comportamento das filas, verificando sua variabilidade ao longo dos dias e como sua frequência se altera em relação aos minutos em que o refeitório funciona. Isso foi feito por meio das análises dos dados tratados, a fim de verificar as potencialidades que pudessem ser implementadas.

\subsubsection{Regressão usando Redes Neurais Artificiais}

Buscou-se, com uma regressão, averiguar qual seria o intervalo médio de tempo para cada fatia de horário de 30 segundos, dentro do atendimento. Assim sendo, a ideia principal consistiu em:

- Fazer as diferenças de tempo entre os usuários da fila, para os 20 dias de coleta, gerando, assim, 20 séries de intervalos de tempo;

- Criar uma régua de agrupamento a cada espaço de 30s, uma vez que, o número de pessoas por dia varia. Dessa maneira, entre a abertura (10:30:00) e 
o fechamento (12:00:00) do refeitório, calcularamse a média, a mediana, a quantidade de pessoas, o desvio-padrão e o coeficiente de variação dos intervalos em cada faixa de $30 \mathrm{~s}$, para o respectivo dia. Criaram-se, assim, 20 novas séries, com 180 intervalos, em que cada posição possuía todos os cálculos na sua fatia respectiva. Na Figura 10, há a representação desse processo para as médias;
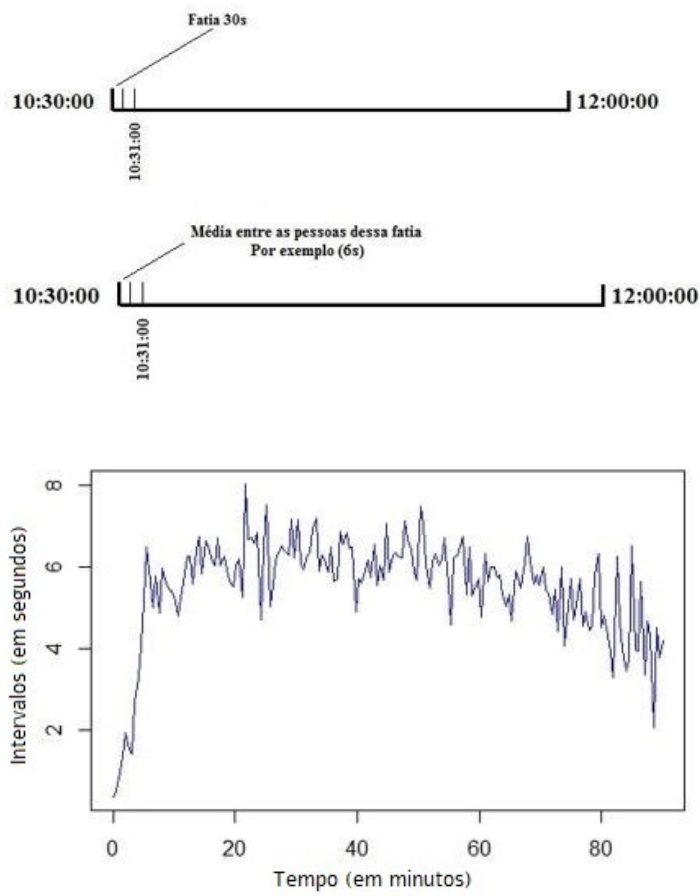

Figura 10: Cálculo da média para os intervalos/Representação gráfica da série gerada

Fonte: acervo do autor

- Tornar aleatórias as 20 séries calculadas, a fim de remover padrões durante os dias do refeitório. Assim sendo, separaram-se 15 para o treinamento, e as outras cinco para testes, ao passo que, para as 15, foi gerada um série final com a média de cada cálculo respectivo entre estas, realizando-se o treinamento da RNA, obtendo-se uma regressão a ser testada. Os valores da quantidade de usuários, mediana, desvio-padrão e coeficiente de variação foram usados como parâmetros na entrada da rede, visando refletir em uma saída com a média dos intervalos de tempos;

- Padronizar os valores antes de serem inseridos na RNA, na faixa entre 0 e 1, utilizando-se a Equação 1. Esse procedimento é realizado, pois reduz a possibilidade de as entradas da RNA, após elas serem ponderadas pelos pesos respectivos, caírem em uma faixa denominada saturação, reduzindo, assim, o desempenho da rede.

$$
\frac{S i-S \min }{S \max -S \min }
$$

Em que $S i$ refere-se ao elemento a ser convertido; Smin, o menor valor que se encontra no intervalo; e $S \max$, o maior valor encontrado no intervalo em questão.

- Com a regressão obtida, foi colocada em teste a rede treinada, objetivando-se calcular as diferenças em relação aos resultados (valores preditos) e os valores esperados (intervalos médios de tempos), para cada ponto da regressão gerado. Isso foi feito em cada uma das cinco séries restantes. E, por fim, realizou-se a plotagem de gráficos comparativos, bem como os cálculos das métrica de avaliação.

Dessa forma, esperou-se que, ao final, com a função gerada (abstração da RNA treinada), cada entrada de uma fatia de horário, que representa um usuário se inserindo no contexto de atendimento, gerasse uma saída. E assim, todo o contexto de comportamento da fila fosse previsto, podendo esse resultado indicar picos de atendimento e horários de menor demanda.

A RNA foi treinada com um número de neurônios igual a 10 e um número de épocas igual a 10.000. Entre os outros parâmetros, estão a faixa de inicialização aleatória dos pesos, sendo esta $[-0,3 ; 0,3]$, e uma taxa de aprendizagem de 0,35. O valor do bias configurado na rede foi de -1 , com as funções de ativação sendo tangente hiperbólica, para a camada escondida, e função linear na camada de saída. Tais valores foram calibrados manualmente, variando um dos parâmetros, enquanto todos os outros permaneciam fixados, ao passo que eram observados os erros de época a época para cada teste.

Nesse sentindo, ao notar que a convergência da rede melhorava, continuava-se o processo até uma estagnação, passando, assim, para um novo parâmetro com os mesmos procedimentos. A topologia da rede montada pode ser visualizada na Figura 11 .

\subsection{Métricas de avaliação}

Para se fazer um estudo comparativo, as saídas geradas pela RNA, junto aos dados reais de um dia no refeitório, foram empregadas em métricas para verificar o quão dispersos os resultados ficaram em relação aos dados reais. Para isso, as duas principais medidas utilizadas foram REQM e o POCID.

\subsubsection{Raiz do Erro Quadrático Médio (REQM)}

Essa métrica é utilizada para avaliar estatisticamente resultados nas mais diversas situações. O REQM equivale 


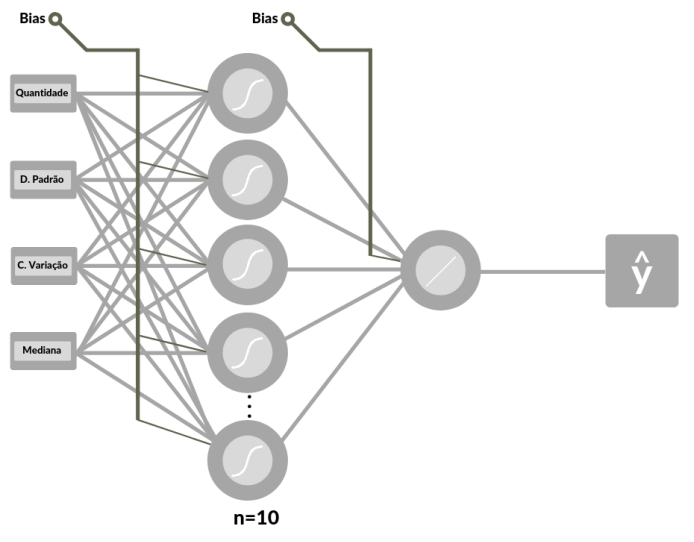

Figura 11: Topologia da RNA proposta

Fonte: acervo do autor

à raiz da distância Euclideana média entre as estimativas e os correspondentes parâmetros, apresentados na Equação (2).

$$
R E Q M=\sqrt{\sum_{i} \frac{\left(y_{i}-\hat{y}\right)^{2}}{n}}
$$

Em que $\sum_{i}$ é o somatório de $n$ termos, sendo $y_{i}$ o valor estimado; $\hat{y}$, o valor real; e $n$, a quantidade total de termos. Assim, é caracterizado pela raiz da soma das diferenças entre o valor de $y_{i}$ e $\hat{y}$, elevado ao quadrado, controlado pelo número de elementos.

\subsubsection{Prediction On Change In Direction (POCID)}

A métrica POCID é utilizada para cálculo de percentual de acerto quanto à previsão da alteração da direção, no caso de séries temporais, ou seja, suas subidas e descidas. A sua representação é dada na Equação (3).

$$
P O C I D=100 \frac{\sum_{t=1}^{n} D_{t}}{n}
$$

Sabendo-se que:

$$
\begin{cases}D_{t}=1 & , \text { se }\left(\operatorname{targ}_{t}-\operatorname{targ}_{t-1}\right) \cdot\left(\text { out }_{t}-\text { out }_{t-1}\right)>0 \\ D_{t}=0 & , \text { caso contrário. }\end{cases}
$$

Em que target representa os elementos reais, sendo $t$ referente ao momento do somatório, e output, aos valores de saída da RNA. Já $n$ diz respeito à quantidade total de elementos. O POCID terá resultado entre 0 e 100, e, quanto mais próximo de 100, melhor será o modelo de previsão.

Tais métricas foram importantes, pois demonstraram o quanto estava sendo efetivo o algoritmo no trabalho realizado, ao mesmo tempo que permitiu comparações entre essas para uma discussão mais efetiva dos resultados. Assim sendo, as métricas possibilitaram verificar o comportamento dos testes.

\section{Resultados}

Aplicado os passos da metodologia, partiu-se, então, para a análise dos resultados obtidos pela RNA, verificando as melhores performances durante os testes realizados, como demonstrado na Figura 12, para o erro iterativo de época a época pode-se observar como a convergência da rede se comportou durante a etapa de treinamento.
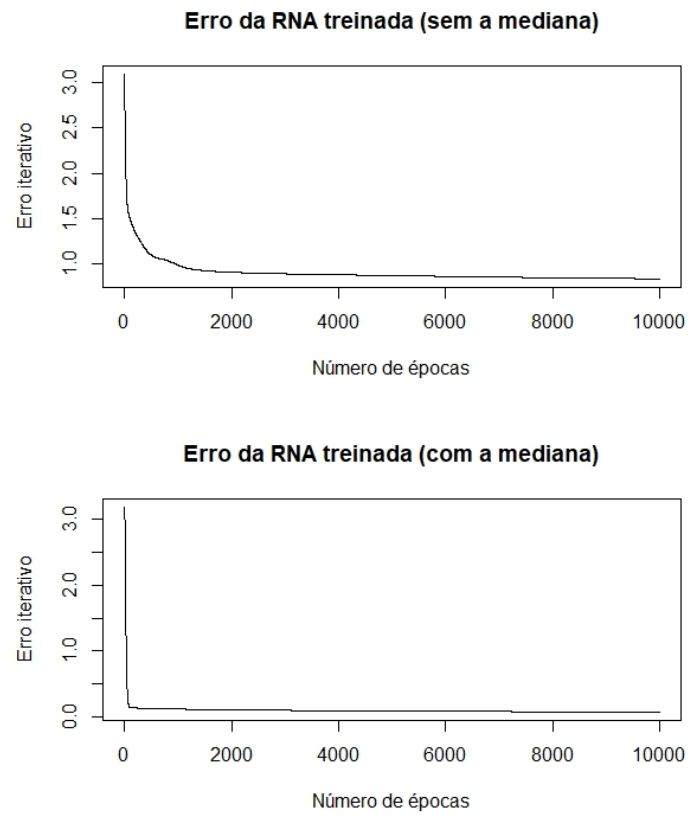

Figura 12: Comparativo do erro iterativo época a época

Fonte: acervo do autor

Com o modelo gerado, foram realizados cinco testes com as amostras de treino. Nesse sentido, foram plotados gráficos comparativos entre os valores esperados e os preditos, bem como dois gráficos para cada teste, sendo um desses sem os valores de mediana, inseridos no treinamento da rede, e outro com a mesma inserida. Isso foi feito porque o cálculo da mediana foi o parâmetro que mais ajustou a rede, para atingir o valor real dos intervalos médios, em cada fatia de tempo. Esse fato acontece porque a mediana não é afetada por valores extremos, representando a centralização dos dados de maneira mais eficiente. Os gráficos podem ser vistos nas Figuras 13 a 17. 
Teste 1 (sem mediana)

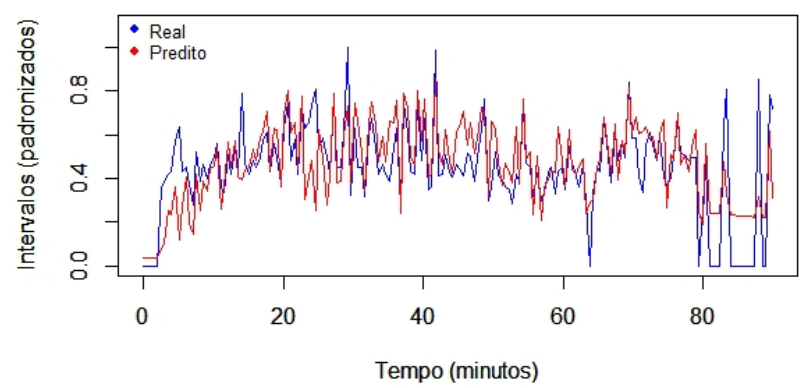

Teste 1 (com mediana)

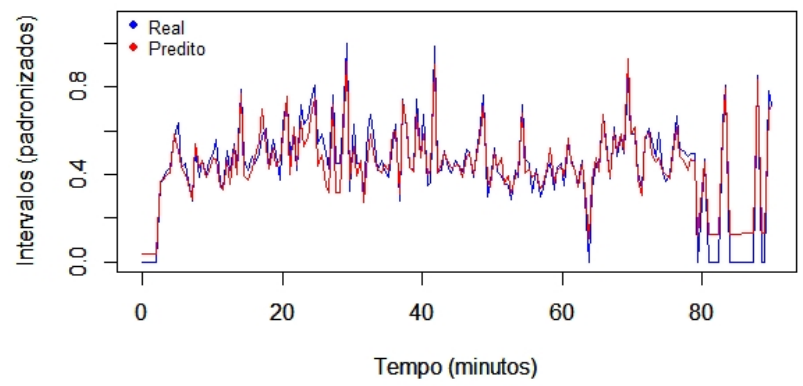

Figura 13: Comparativo Teste 1

Fonte: acervo do autor

Teste 2 (sem mediana)

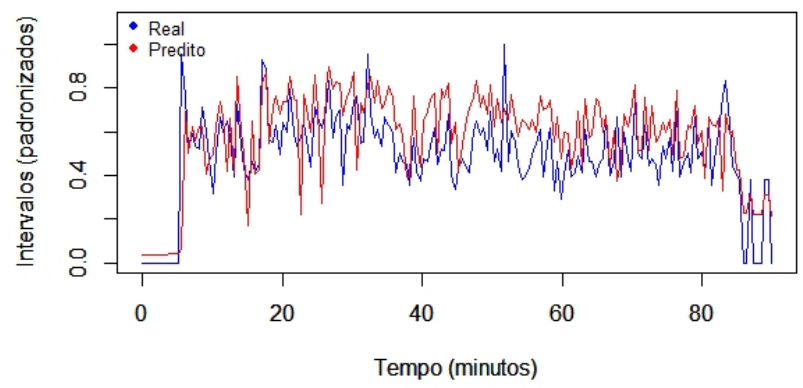

Teste 2 (com mediana)

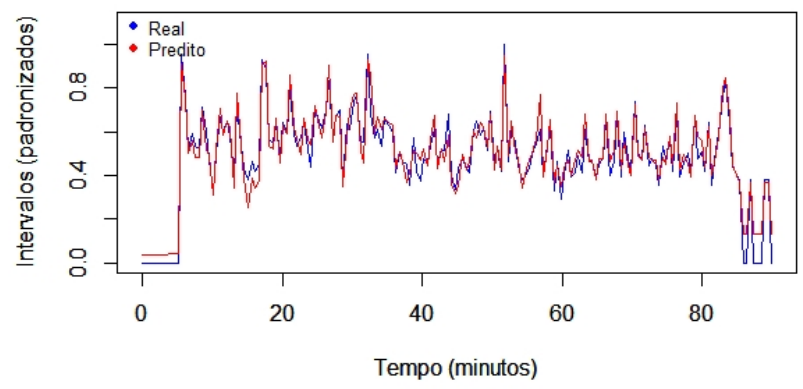

Figura 14: Comparativo Teste 2

Fonte: acervo do autor
Teste 3 (sem mediana)

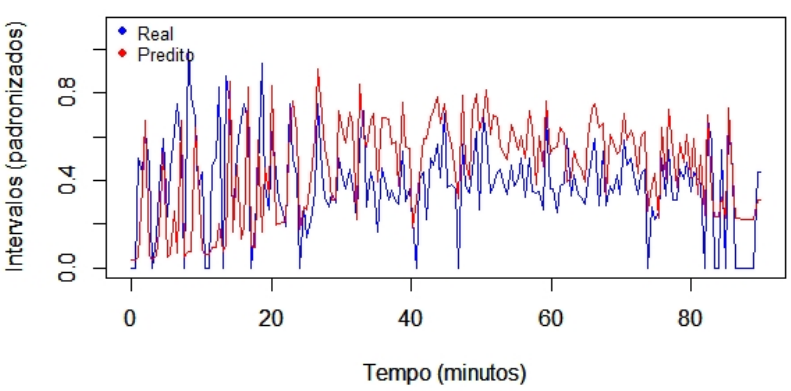

Teste 3 (com mediana)

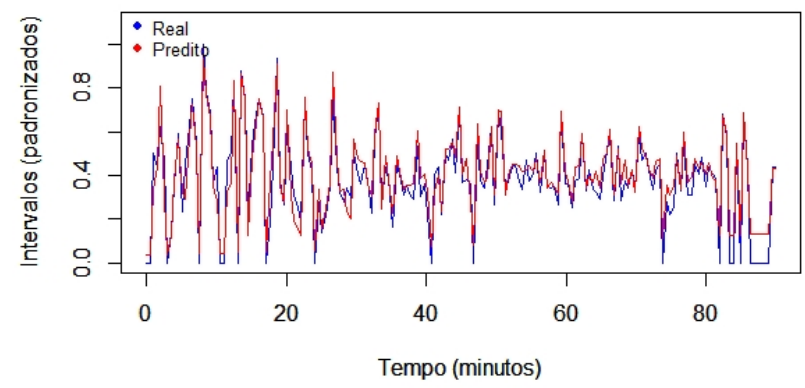

Figura 15: Comparativo Teste 3

Fonte: acervo do autor
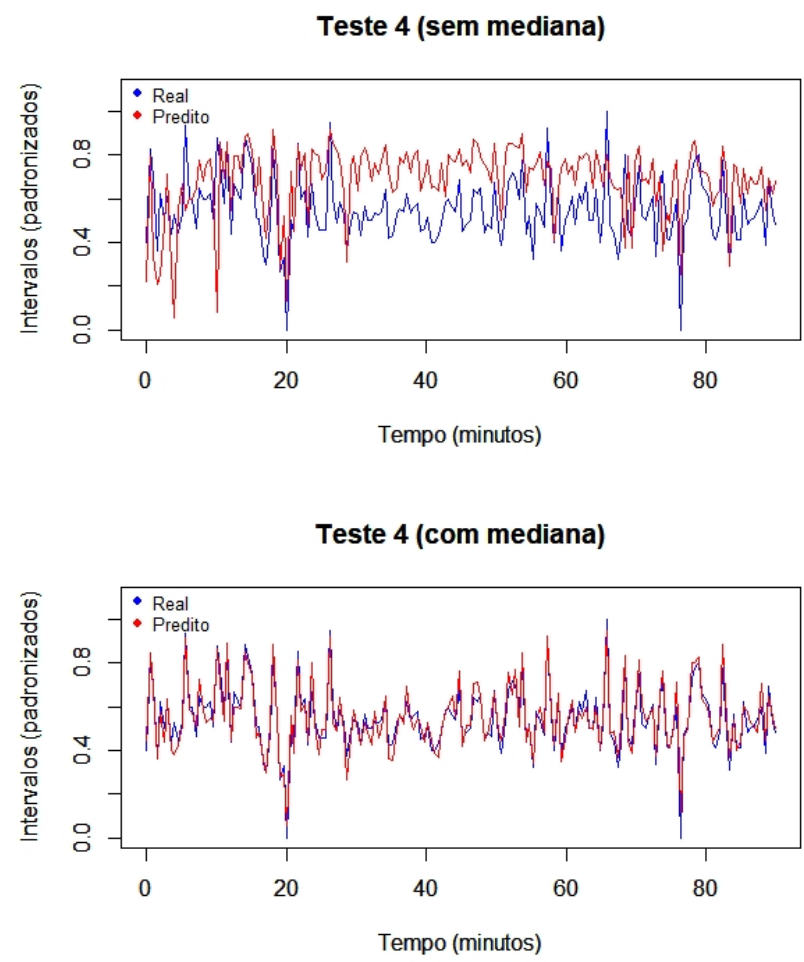

Figura 16: Comparativo Teste 4

Fonte: acervo do autor 
Teste 5 (sem mediana)

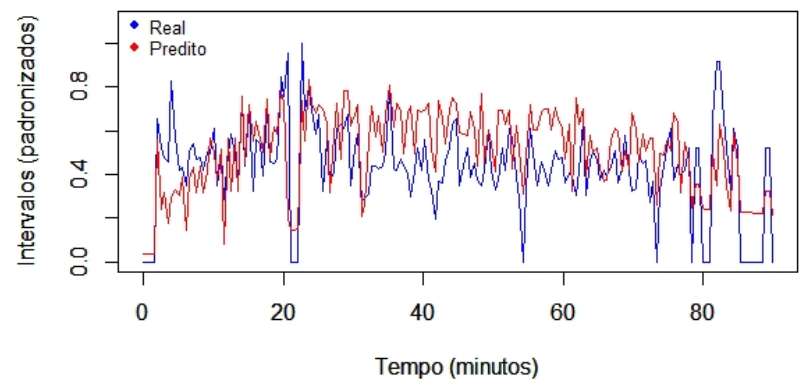

Teste 5 (com mediana)

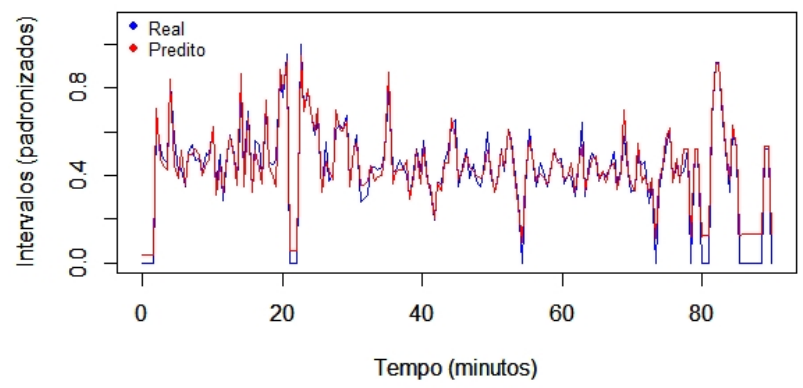

Figura 17: Comparativo Teste 5

Fonte: acervo do autor

Como se pode notar, no comparativo dos gráficos, ficou demonstrado que o uso da mediana influenciou bastante no comportamento da predição, descrevendo graficamente resultados similares aos reais. Já quanto à REQM e POCID, podem ser vistas as Tabelas 1 e 2, seguindo a mesma linha de comparação feita anteriormente com a mediana, para seus valores.

Tabela 1 Cálculos de REQM.

\begin{tabular}{|l|l|l|}
\cline { 2 - 3 } \multicolumn{1}{c|}{} & sem mediana & com mediana \\
\hline Teste 1 & 0,154 & 0,062 \\
\hline Teste 2 & 0,173 & 0,050 \\
\hline Teste 3 & 0,244 & 0,066 \\
\hline Teste 4 & 0,208 & 0,048 \\
\hline Teste 5 & 0,196 & 0,054 \\
\hline
\end{tabular}

Analisando-se os valores da Tabela 1 nota-se que sem a mediana, eles ficaram na faixa de $15,4 \%$ a $24,4 \%$ de erro. Já com a inserção desta como parâmetro de entrada, o erro passou a ficar na faixa de $4,8 \%$ a $6,6 \%$, podendo-se notar uma melhora nos resultados por volta de $10 \%$ quando analisada a métrica de REQM.

Com o POCID, a faixa de acerto do direcionamento, de acordo com a regressão gerada sem a mediana, se deu entre $60,5 \%$ e $77,2 \%$, e, com ela, teve-se uma faixa de acerto de $79,4 \%$ a $86,1 \%$, havendo assim, uma melhora por volta de $12 \%$, em média.

Apesar das métricas serem de contexto bem diferentes, é interessante notar algumas análises. Quando ob-
Tabela 2 Cálculos de POCID.

\begin{tabular}{|l|l|l|}
\cline { 2 - 3 } \multicolumn{1}{c|}{} & sem mediana & com mediana \\
\hline Teste 1 & $70 \%$ & $79,4 \%$ \\
\hline Teste 2 & $70,5 \%$ & $82,7 \%$ \\
\hline Teste 3 & $70,1 \%$ & $86,1 \%$ \\
\hline Teste 4 & $77,2 \%$ & $85 \%$ \\
\hline Teste 5 & $60,5 \%$ & $80 \%$ \\
\hline
\end{tabular}

servadas as variações dos valores com e sem a mediana, para os testes um e dois, eles se mostraram bastante condizentes quando comparados os valores de REQM e POCID, pois, ao passo que o primeiro diminuiu, o segundo aumentou, respectivamente, quase na mesma proporção. Já para os testes três, quatro e cinco, essa equivalência não se deu de forma tão acentuada, mas claramente na mesma direção.

Ainda no raciocínio comparativo, destacam-se o testes três e cinco, devido ao fato de suas variações entre as métricas terem sido bastante diferentes. Isso pode ser justificado, primeiramente, observando-se como se deu o comportamento visual do dia analisado por meio dos gráficos, notando-se uma oscilação muito mais acentuada, o que induz a uma dificuldade maior de ajuste da rede. Há, também, alguns quesitos externos que podem ser influenciadores nesse sentido. Por exemplo, dias próximos a feriados, que ocorreram durante as coletas, o que interferiu bastante no comportamento da fila, bem como outros fatores, por exemplo, dias de sexta-feira, que, em geral, possuem um fluxo mais variável, sendo isso observado durante as coletas.

Assim sendo, considerando-se todas essas análises, pôde-se verificar que os resultados atingidos foram desejáveis, indicando uma boa atuação da RNA no papel da predição dos intervalos. Os valores de REQM foram relativamente baixos, sendo que, quanto menores, melhor o desempenho da rede. Já os valores do POCID demonstraram-se bons, uma vez que eles mostram se as alterações dos valores comparados a cada iteração (real e predito) aconteceram na mesma direção.

\section{Conclusões}

O principal intuito deste trabalho foi aplicar conhecimentos, desde a metodologia científica em experimentos, passando por análises estatísticas, até a aplicação de técnicas computacionais, todas essas com a finalidade do estudo de caso feito no refeitório do IFMG-Campus Bambuí, objetivando predizer intervalos de tempos, por meio dos datasets montados. Os resultados se mostraram promissores, pois atingiram as expectativas desejadas. E muito mais importante, foi necessário um rigor técnico para que este estudo fosse realizado.

Alguns pontos foram observados fora do contexto da RNA ao longo do experimento. Os tipos de alimentos e talheres dispostos para os usuários refletem diretamente no tempo e velocidade que a fila anda. $\mathrm{O}$ fato de um garfo grande - de dois dentes - ser colocado para servir espa- 
guete causou um gargalo considerável, fazendo com que o atendimento terminasse fora do horário determinado, por exemplo.

A limitação do cronograma e o processo não automatizado de coleta acabaram por não permitir resultados mais enfáticos. O ideal seria um sistema automatizado totalmente dedicado a esse objetivo. Com a implantação do novo sistema de pagamento, a automatização do processo pode ser facilitada, ficando como sugestão de continuidade para o estudo, uma vez que amostras mais robustas permitem que a RNA aumente sua performance.

A demanda de atendimento no refeitório, ao longo dos dias, sofre influência de alguns fatores, como feriados e também os horários dispostos, que cada pessoa tem ao longo de sua vida acadêmica. Assim, não se pode afirmar que o comportamento de duas quintas feiras serão parecidos. Isso faz com que o processo se torne mais complexo, ao passo que o uso de dados estatísticos se tornou mais desafiador para formar as estratégias empregadas.

Outro ponto para continuidade refere-se à aplicação de outros métodos para previsão, fazendo um comparativo de resultados. Nota-se que a área referente à Ciência de Dados é muito extensa, tornando sua aplicabilidade muito ampla, podendo ser desde o uso de uma RNA até a fusão de várias outras técnicas, atingindo objetivos como previsão e otimização em dados e processos.

\section{Referências}

[1] Marisa Baptistella, Maria Teresinha Arns Steiner, and Anselmo Chaves Neto. O uso de redes neurais e regressão linear múltipla na engenharia de avaliações: Determinação dos valores venais de imóveis urbanos. Diss., Universidade Federal do Paraná, 2005 .

[2] Vic Barnett and Toby Lewis. Outliers in statistical data. Wiley, 1974.

[3] Ivan Nunes da Silva, Danilo Hernane Spatti, and Rogério Andrade Flauzino. Redes Neurais Artificiais Para Engenharia E Ciências Aplicadas Curso Prático. ARTLIBER, 2010.

[4] Antônio de Pádua Braga, A. P. L. F. Carvalho, and Teresa Bernarda Ludemir. Fundamentos de redes neurais artificiais. Rio de Janeiro: 11a Escola de Computação, 1998.

[5] Norman Gaither and Greg Frazier. Administração da produção e operações. Pioneira Thomson Learning, 2001.

[6] Ricardo André Guarnieri. Emprego de redes neurais artificiais e regressão linear múltipla no refinamento das previsões de radiação solar do modelo eta. Master's thesis, 2006.

CALIBRE - Revista Brasiliense de Eng enharia e Física Aplicada, ISSN 2526-4192. Livre direito de cópia de acordo com os primcípios estabelecidos pela Creative Commons.
[7] Francielly Hedler Staudt, Mirian Buss Gonçalves, and Carlos Manuel Taboada Rodriguez. Procedimento para implantar um modelo de previsão de demanda com incorporação de julgamento de especialistas. Production, 26(2), 2016.

[8] Masoud Mahmoodi and Ali Naderi. Applicability of artificial neural network and nonlinear regression to predict mechanical properties of equal channel angular rolled al5083 sheets. Latin American Journal of Solids and Structures, 13(8):1515-1525, 2016.

[9] G Manuel and JHC Pretorius. The significance of relevance trees in the identification of artificial neural networks input vectors. Journal of Energy in Southern Africa, 24:00 - 00, 012013.

[10] Daniel Augusto Moreira. Administração da produção e operações. São Paulo, 2009.

[11] Benício Barros Neto, Ieda Spacino Scarminio, and Roy Edward Bruns. Como Fazer Experimentos: Pesquisa e Desenvolvimento na Ciência e na Indústria. Bookman Editora, 2001.

[12] Bruno Alberto Soares Oliveira, Servílio Assis, and Carlos Nolli. Development of a prototype electrical energy monitoring system via internet/desenvolvimento de um protótipo de sistema de monitoramento de energia elétrica via internet. Revista de Engenharia da Universidade Católica de Petrópolis, 12(1):48-61, 2019.

[13] Bruno Alberto Soares Oliveira, Matheus Soares Nametala, Brayan Rawlison Castoril, Marcos Diego Catalano, and Ciniro Aparecido Leite Nametala. Avaliação de uma rede neural artificial como estimador temporal pluviométrico no sistema de abastecimento cantareira. Revista de Informática Aplicada, 14(1), 2018.

[14] Andy Pole, Mike West, and Jeff Harrison. Applied Bayesian forecasting and time series analysis. Chapman and Hall/CRC, 2018.

[15] Clemens Reimann, Peter Filzmoser, Robert Garrett, and Rudolf Dutter. Análise estatística dos dados explicada: estatística ambiental aplicada com $\overline{\text { R. Number Sirsi) i9780470985816. Wiley Online Li- }}$ brary, 2008.

[16] Adolfo Rene Santa Cruz Rodriguez and Camila Corrêa. Previsión de demanda intermitente con métodos de series de tiempo y redes neuronales artificiales: Estudio de caso. Dyna, 84(203):9-16, 2017.

[17] Caston Sigauke. Forecasting medium-term electricity demand in a south african electric power supply system. Journal of Energy in Southern Africa, 28(4):54-67, 2017. 
[18] Panarat Srisaeng, Glenn Baxter, Steven Richardson, and Graham Wild. A forecasting tool for predicting australia's domestic airline passenger demand using a genetic algorithm. Journal of Aerospace Technology and Management, 7(4):476$489,2015$.

[19] Josimar Tello-Maita and Agustín MarulandaGuerra. Modelos de optimización para sistemas de potencia en la evolución hacia redes inteligentes: Una revisión. Dyna, 84(202):102-111, 2017.

[20] Marisol Valencia-Cárdenas, Francisco Javier DíazSerna, and Juan Carlos Correa-Morales. Multiproduct inventory modeling with demand forecasting and bayesian optimization. DYNA, 83(198):235-243, 2016.

[21] Andreas S Weigend. Time series prediction: forecasting the future and understanding the past. Routledge, 2018.

[22] Bogdan M Wilamowski and J David Irwin. Intelligent systems. CRC press, 2018.

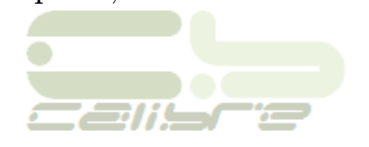

